\title{
Distribution and risks of polycyclic aromatic hydrocarbons in suburban and rural soils of Beijing with various land uses
}

\author{
Chi Peng • Meie Wang • Yun Zhao • Weiping Chen
}

Received: 25 May 2015 / Accepted: 3 February 2016/Published online: 15 February 2016

(C) Springer International Publishing Switzerland 2016

\begin{abstract}
We investigated the sources, distribution, and health risks of polycyclic aromatic hydrocarbons (PAHs) in soils of peri-urban Beijing. The mean concentrations of total 16 PAHs in suburban and rural soils of Beijing were $321.8 \pm 408.2$ and $219.2 \pm 233.5 \mathrm{ng} / \mathrm{g}$, respectively. The PAH concentrations decreased along the urban-suburban-rural gradient and varied with land use categories. The industrial areas had the highest soil PAH concentrations followed by the living areas, roadsides, green areas, and agricultural areas. The major sources of PAHs in these soils were coal and biomass combustion. Traffic emission was not the dominant source of PAHs in peri-urban Beijing. At a few sites, high soil PAH contents were caused by point sources such as iron and steel plants and a wood preservative factory. The incremental lifetime cancer risks (ILCRs) of adults and children exposed to PAHs in the soils were acceptable. However, cautions should be paid to the abandoned industrial sites, which might be converted to residential area during the urbanization process.
\end{abstract}

Electronic supplementary material The online version of this article (doi:10.1007/s10661-016-5156-z) contains supplementary material, which is available to authorized users.

C. Peng $\cdot$ M. Wang $\cdot$ Y. Zhao $\cdot$ W. Chen $(\bowtie)$

State Key Laboratory of Urban and Regional Ecology, Research Center for Eco-environmental Sciences, Chinese Academy of

Sciences, Beijing 100085, People's Republic of China

e-mail:wpchen@rcees.ac.cn
Keywords Health risk assessment $\cdot$ Land use change . Suburban $\cdot$ Urbanization $\cdot$ PAHs $\cdot$ ILCRs

\section{Introduction}

Most of the polycyclic aromatic hydrocarbons (PAHs) in the environment originated from incomplete combustion processes such as fossil fuel combustion, biomass burning, volcanoes, and wildfires (Aichner et al. 2007; Liu et al. 2014). PAHs are also resulted from petroleum products or oil spills as secondary sources. Once released into the environment, PAHs can undergo long-range transport along with airflows and water circulation (Sun et al. 2009). The omnipresence of PAHs in the polar regions and snowy mountains has been well documented (Nam et al. 2008; Wang et al. 2007). The emission and accumulation of PAHs have aroused broad concerns due to their carcinogenic toxicity to human health (Ma et al. 2015; Vane et al. 2014; Wang et al. 2015).

Urban areas are the geographic center of PAH sources (Wong et al. 2004). The dense traffic, industrial activities, daily cooking, and winter heating of urban residents emit considerable amounts of PAHs into the urban environment (Heywood et al. 2006; Liu et al. 2006). PAHs are lipophilic chemicals that are prone to adsorb onto soil particles. Consequently, soil serves as a PAH source and sink in urban areas, accumulating PAHs from processes such as atmospheric deposition and water irrigation (Aichner et al. 2007; Bu et al. 2009). The characteristics of PAHs in urban soils have been helpful in understanding the long-term history of pollution and 
their connection with urbanization and industrialization (He et al. 2009; Peng et al. 2015).

On the landscape scale, the spatial variation of $\mathrm{PAH}$ concentrations in soils can be largely explained by power use and the location of pollution sources. The land use classifications reflecting the features of PAH sources and urbanization progression consequently affect PAH distributions in soils (Zheng et al. 2011). Industrial activities and heavy traffic can significantly elevate the soil PAH contents in neighboring areas (Peng et al. 2012). Soil PAH concentrations have been positively correlated with local census data including population density, traffic density, and GDP (Wang et al. 2010). Clear gradients of $\mathrm{PAH}$ concentrations from urban to rural soils were found in both northern and southern China (Wang et al. 2007; Xiao et al. 2014).

PAHs in suburban areas may diffuse from downtown areas or be emitted from local sources (Feng et al. 2013). The structures and functions of land uses in suburban areas exhibit a mixture of the characteristics of urban and rural areas. Mixed sources such as petroleum, traffic emissions, and biomass and coal combustion have contributed to PAH accumulation in suburban soils (Xiao et al. 2014). The large differences in traffic, population density, and lifestyle between the newly developed towns and the old-fashioned farming villages led to spatially unbalanced PAH emissions. Some supporting function areas of cities located in suburban areas such as industrial areas, sewage treatment areas, and landfill sites are probably polluted with PAHs (Augusto et al. 2009; Tao et al. 2004). The concentrations of PAHs in suburban soils are expected to vary with land use categories.

The rural areas have relatively uniform landscape, composed of agricultural lands, living areas, and uncultivated green areas. In the agricultural lands, the PAHs derive from wastewater irrigation and open burning of brushwood and straw (Ravindra et al. 2008; Tao et al. 2004). The living areas, such as villages and small towns, are scattered in the landscape matrix of cultivated land. Wood and coal usage for cooking or heating are the major PAH sources in these farming villages (Liu et al. 2014). Biomass burning and domestic coal combustion are the major PAH sources in the rural areas of China (Liu et al. 2006). Air diffusion from urban areas may be an important input of PAHs to downwind rural areas. The low-density traffic in rural areas would release some PAHs into the environment.
Risk assessments of PAHs deposited in urban soils and road dust have been widely conducted to evaluate the environmental consequences of urbanization (Peng et al. 2011, 2013; Wang et al. 2011, 2013). The rapid urban sprawl in China has caused the transformation of suburban villages and former industrial areas to highly populated urban settlements. The soils contaminated with PAHs in the peri-urban areas could become a threat to urban residents when land use changes take place. Compared with urban areas, fewer studies have focused on the risks associated with PAHs in the suburban and rural areas. Therefore, knowledge on the sources, distribution, and risk assessment of PAH accumulation in suburban and rural soils is important to urban planning.

Beijing was once a highly industrialized city and currently is characterized by hyper-dense traffic and habitation equipped with coal heating systems. The sources, distribution, and potential risks of PAHs in the urban soils of Beijing have been investigated (Peng et al. 2011, 2012). In this study, we focused on PAHs in the suburban and rural soils of Beijing. The purposes were (1) to investigate the concentrations and sources of PAHs in suburban and rural soils of Beijing, (2) to study the PAH distributions in suburban and rural soils of Beijing with various land uses, and (3) to assess the potential risks of local residents exposed to soil PAHs in peri-urban Beijing.

\section{Material and methods}

\section{Soil sampling}

The sampling sites were spatially balanced in the suburban and rural areas of Beijing, including Tongzhou District and the area between the fifth and sixth ring roads (Fig. 1). The urban sprawl of Beijing expanded outward, leading to the formation of seven concentric ring roads. The fifth ring road has been commonly considered the boundary between the urban and suburban areas of Beijing. The area between the fifth and sixth ring roads was identified as suburban Beijing. Tongzhou District is in the downwind area of Beijing and can be divided into two parts by the sixth ring road (Fig. 1). The part outside the sixth ring road was selected to represent the rural area of Beijing.

Prior to the sampling process, the study area was divided into $3 \times 3-\mathrm{km}$ grids. Sampling sites were chosen based on the remote sensing image to represent the 


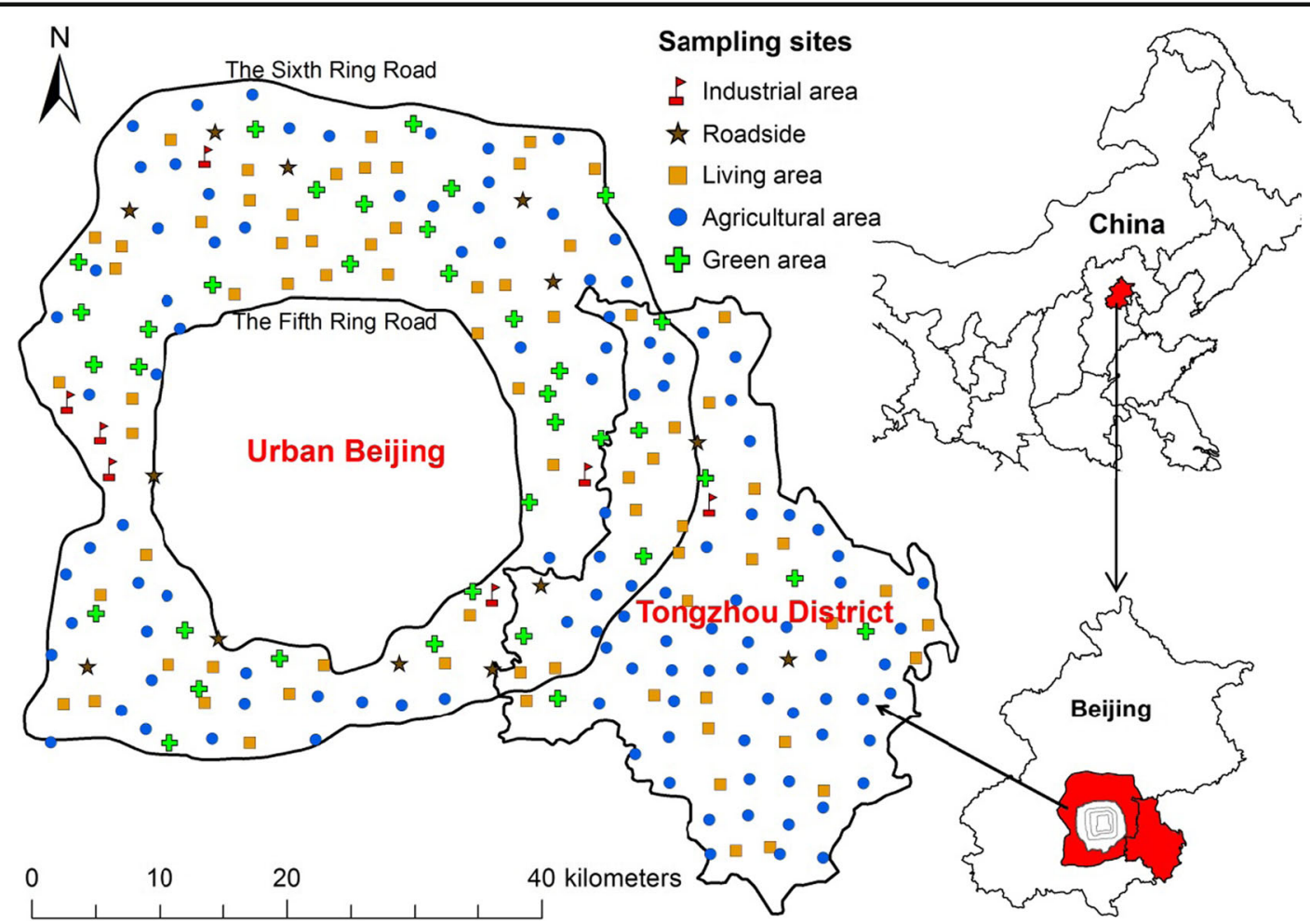

Fig. 1 The distribution and land use classification of sampling sites in peri-urban Beijing

dominant land uses in each grid (Fig. 2). A total of 237 samples out of 243 grids were obtained in September 2010 , including industrial area $(n=7)$, roadside $(n=13)$, living area (residential area and villages, $n=70)$, agricultural area $(n=111)$, and green area (parks, forests, and uncultivated land, $n=36$ ). Each sample was the mixture of five subsamples around the designated location and was transported to the laboratory in plain paper bags. Prior to extraction, soil samples were air-dried at room temperature, ground to pass a $0.1-\mathrm{mm}$ sieve, and stored in amber color containers at $-25^{\circ} \mathrm{C}$.

\section{PAH analysis}

The PAH concentrations in the soil samples were measured using a three-step process of extraction, purification, and quantification. In the extraction procedure, $10 \mathrm{~g}$ of each soil sample was mixed with 3-g diatomaceous earth and $1-\mathrm{ml}$ surrogate standard solution in a sealed vessel, then extracted by an Accelerated Solvent Extractor 350 (Dionex, Sunnyvale, CA, USA) with 1:1 acetone-dichloromethane solvent $(v / v)$. The extraction program was set to $5 \mathrm{~min}$ of heating time, $100{ }^{\circ} \mathrm{C}$ of oven temperature, $6 \mathrm{~min}$ of static extraction time, $60 \%$ flush volume, $1500 \mathrm{psi}$ of cell pressure, and 2 cycles. To purify the extract, a silica gel solid-phase extraction column (Supelco silica-gel column) with $1 \mathrm{~g}$ of anhydrous sodium sulfate added on the top end was primed with $5 \mathrm{ml} n$-hexane. The extract was concentrated to $2 \mathrm{ml}$ with a rotary evaporator and then eluted with $8 \mathrm{ml}$ of $1: 1 \mathrm{n}$-hexane-dichloromethane solvent $(v / v)$ from the top of the silica gel column. The eluate was further concentrated to $1 \mathrm{ml}$ under a gentle stream of nitrogen gas for the quantification procedure.

The PAH concentrations were measured by an Agilent 6890 gas chromatography system equipped with a 5975C mass selective detector (GC-MSD; Agilent Inc., CA). The initial oven temperature was $50{ }^{\circ} \mathrm{C}$, held for $1 \mathrm{~min}$, then raised to $150{ }^{\circ} \mathrm{C}$ at $25^{\circ} \mathrm{C} / \mathrm{min}$ and held for $1 \mathrm{~min}$, and finally raised to $300{ }^{\circ} \mathrm{C}$ at $4{ }^{\circ} \mathrm{C} / \mathrm{min}$, held for $10 \mathrm{~min}$. The selective ion monitoring (SIM) mode was set to detect only the internal standards (2-fluorobiphenyl and 4-terphenyl-d 14; AccuStandard, USA) and the 16 US Environmental Protection Agency (USEPA) priority PAHs, namely, naphthalene (NAP), acenaphthylene (ACPY), acenaphthene (ACP), fluorene (FL), phenanthrene (PHE), anthracene (ANT), fluoranthene (FLT), pyrene 
(PYR), chrysene (CHR), benzo(a)anthracene (BaA), benzo(k)fluoranthene $(\mathrm{BkF})$, benzo(b)fluoranthene $(\mathrm{BbF})$, benzo(a)pyrene $(\mathrm{BaP})$, dibenzo(a,h)anthracene (DBA), indeno(1,2,3-cd)pyrene (IND), and benzo(g,h,i)perylene (BghiP).

Duplicate samples were analyzed for every five samples to ensure data quality. Five randomly selected soil samples were spiked with $1 \mathrm{ml}$ of PAH standard solution $(2000 \mathrm{ng} / \mathrm{g}$ ) in the sealed vessel prior to the extraction procedure. The matrix-spiked recoveries were carried out by comparing analysis results of the five spiked samples with their initial results. The detailed recoveries for the 16 PAH congeners (between 51 and $95 \%$ ) and the method detection limits were shown in Table S1.
Risk assessment

Soils contaminated with PAHs can threaten the health of urban inhabitants though three pathways, including direct ingestion, dermal contact, and inhalation. We used USEPA standard models to evaluate the incremental lifetime cancer risks (ILCRs) that soil PAHs posed to local residents (Chen and Liao 2006; USEPA 1991; Wang 2007). ILCRs (unitless) calculate exposure frequencies of the three pathways and then multiply by the corresponding carcinogenic slope factors and the toxic equivalent quantity (TEQ) of PAHs in the soils. The equations of ILCRs for the three pathways are

$\mathrm{ILCR}_{\text {ingestion }}=\frac{\mathrm{CS} \times\left(\mathrm{CSF}_{\text {ingestion }} \times \sqrt[3]{(\mathrm{BW} / 70)}\right) \times \mathrm{IR}_{\text {soil }} \times \mathrm{EF} \times \mathrm{ED}}{\mathrm{BW} \times \mathrm{AT} \times 10^{6}}$

$\mathrm{ILCR}_{\text {dermal }}=\frac{\mathrm{CS} \times\left(\mathrm{CSF}_{\text {dermal }} \times \sqrt[3]{(\mathrm{BW} / 70)}\right) \times \mathrm{SA} \times \mathrm{AF} \times \mathrm{ABS} \times \mathrm{EF} \times \mathrm{ED}}{\mathrm{BW} \times \mathrm{AT} \times 10^{6}}$

$\mathrm{ILCR}_{\text {inhalation }}=\frac{\mathrm{CS} \times\left(\mathrm{CSF}_{\text {inhalation }} \times \sqrt[3]{(\mathrm{BW} / 70)}\right) \times \mathrm{IR}_{\text {air }} \times \mathrm{EF} \times \mathrm{ED}}{\mathrm{BW} \times \mathrm{AT} \times \mathrm{PEF}}$

where CS is the PAH TEQ in soils $\left(\mathrm{mg} \mathrm{kg}^{-1}\right)$; CSF are carcinogenic slope factors for the three pathways $\left(\mathrm{mg} \mathrm{kg}{ }^{-1} \mathrm{day}^{-1}\right)^{-1}$; EF is the exposure frequency (day year ${ }^{-1}$ ); $\mathrm{ED}$ is the exposure duration (year); $\mathrm{IR}_{\text {air }}$ is the inhalation rate $\left(\mathrm{m}^{3}\right.$ day $\left.{ }^{-1}\right)$; $\mathrm{IR}_{\text {soil }}$ is the soil intake rate $\left(\mathrm{mg} \mathrm{day}^{-1}\right)$; SA, AF, and ABS are the three factors related to dermal exposures such as dermal area $\left(\mathrm{cm}^{2}\right.$ day $\left.{ }^{-1}\right)$, adherence factor $\left(\mathrm{mg} \mathrm{cm}^{-2}\right.$ ), and adsorption fraction; BW is the average body weight $(\mathrm{kg})$; AT is the average life span (day); and PEF is the soil dust production factor $\left(\mathrm{m}^{3} \mathrm{~kg}^{-1}\right)$. The $\mathrm{CSF}_{\text {ingestion, }} \mathrm{CSF}_{\text {dermal }}$, and $\mathrm{CSF}_{\text {inhalation }}$ of BaP were $7.3\left(\mathrm{mg} \mathrm{kg}^{-1} \mathrm{day}^{-1}\right)^{-1}$, $25\left(\mathrm{mg} \mathrm{kg}^{-1} \mathrm{day}^{-1}\right)^{-1}$, and $3.85\left(\mu \mathrm{g} \mathrm{m}^{-3}\right)^{-1} \mu \mathrm{g}$, respectively (Peng et al. 2011). To calculate the total toxicity of soil PAHs, we need to convert the mass concentrations of PAHs to PAH TEQ of BaP based on the toxic equivalency factors (TEFs) in Table 1. Other exposure parameters were provided in Table S2. The total ILCRs were the sums of the ILCR $\mathrm{ingestion}_{\text {, ILCR }}$ dermal, and ILCR $\mathrm{Inhalation}_{\text {. }}$

Data preparation and statistical analysis

The performance of statistical analysis can be affected dramatically by data outliers (Reimann and Filzmoser 2000). We excluded two outliers from the raw dataset prior to statistical analysis processes, which had PAH concentrations 19 times higher than the standard deviations of the rest of samples apparently caused by local point sources rather than regional factors. The two outliers were discussed separately. Then, the PAH data were normalized through the Box-Cox transformation (passed the Kolmogorov-Smirnov test for normal distribution). 
Fig. 2 The distribution of PAH concentrations in suburban and rural soils of Beijing

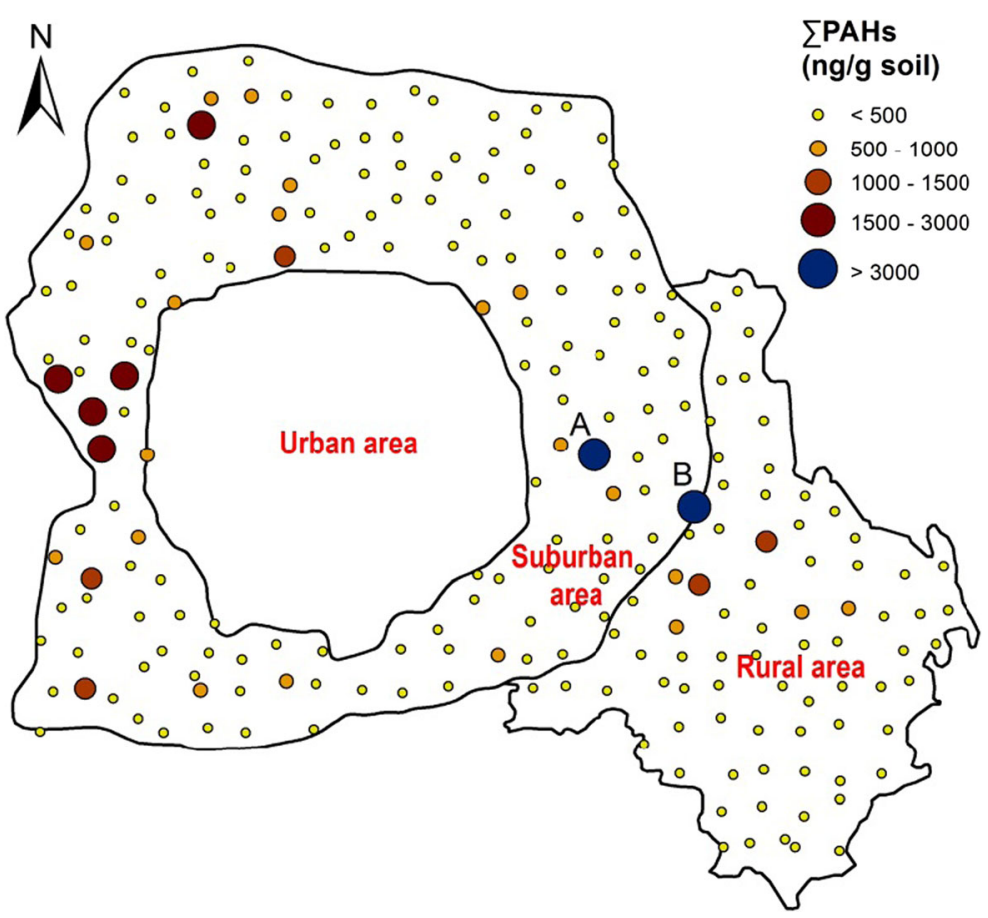

The statistical analysis was carried out with the software SPSS (version 18.0) including KolmogorovSmirnov test, Pearson's correlation analysis, factor analysis with components rotated by the varimax method, and one-way variance analysis with the least significant difference test. The calculations of TEQ and ILCRs were implemented in Excel 2010. ArcGIS 10.0 and Simplot 12.0 were used for the graphic illustrations.

\section{Results and discussions}

PAH concentrations in suburban and rural soil

Table 1 summarizes the statistical results of the $16 \mathrm{PAH}$ concentrations measured in suburban and rural soils of Beijing (the two outliers were not included). The concentrations of the total 16 PAHs in suburban soils ranged from 28.6 to $2571.9 \mathrm{ng} / \mathrm{g}$ with a mean of $321.8 \mathrm{ng} / \mathrm{g}$ and in rural soils ranged from 37.5 to $1245.9 \mathrm{ng} / \mathrm{g}$ with a mean of $219.2 \mathrm{ng} / \mathrm{g}$. We have reported that the mean concentration of the total 16 PAHs in urban soils of Beijing was $1228.1 \mathrm{ng} / \mathrm{g}$ with a standard deviation of $1806.7 \mathrm{ng} / \mathrm{g}$ (Peng et al. 2011). The PAH concentrations decreased sharply along the urban-suburban-rural gradient in the soils of Beijing. The denser traffic, industry, domestic cooking, and heating activities in the urban areas lead to more PAH emissions. Generally, the urban activities increased the PAH contents in urban soils of Beijing $~ 3.8$ times over those of the suburban soils and $\sim 5.6$ times over the rural soils.

Ma et al. (2005) reported a mean PAH concentration of $464 \mathrm{ng} / \mathrm{g}$ measured from 14 surface soils in southern Beijing between the fifth and sixth ring roads in 2001 . To meet the increasing demands of environmental protection, the Beijing government gradually shut down and moved out the heavy industries in the suburban areas of Beijing, banned the use of wastewater irrigation, and encouraged the use of cleaner energy (Wu et al. 2010). Therefore, the PAH concentrations in suburban soils of Beijing may decrease with time.

Table 1 shows that the median values of individual PAH congeners were significantly lower than the mean values, which suggested that the data from a few heavily contaminated sites had elevated the mean concentrations from the median. Peng et al. (2011) classified soil PAH concentrations into four levels $(152,1489,10,304$, and 144,059 ng/g) to represent different levels of potential risk that soil PAHs may pose to local residents. To address the heavy PAH contaminations, we summarized the samples that contained total PAH concentrations more than $1489 \mathrm{ng} / \mathrm{g}$ (Table 2), including two outliers and five samples.

The highest soil PAH concentration was 78,476 ng/g found in a wood preservation plant in southwest Beijing 
Table 1 PAH concentrations and TEF in suburban and rural soils of Beijing (ng/g)

\begin{tabular}{|c|c|c|c|c|c|c|c|c|c|c|c|c|c|c|c|c|}
\hline & \multirow[t]{2}{*}{ Aromatic rings } & \multirow[t]{2}{*}{ TEF } & \multicolumn{7}{|c|}{ Suburban soils $(n=162)$} & \multicolumn{7}{|c|}{ Rural soils $(n=73)$} \\
\hline & & & Min & 25 & 50 & 75 & Max & Mean & SD & Min & 25 & 50 & 75 & Max & Mean & SD \\
\hline NAP & 2 & 0.001 & 4.4 & 9.6 & 13.2 & 19.8 & 149.5 & 19.0 & 18.0 & 3.9 & 9.6 & 12.6 & 17.5 & 68.9 & 14.7 & 9.0 \\
\hline ACPY & 3 & 0.001 & 0.3 & 1.1 & 1.8 & 3.2 & 35.4 & 3.7 & 5.6 & 0.3 & 0.9 & 1.5 & 3.4 & 31.6 & 3.2 & 5.0 \\
\hline $\mathrm{ACP}$ & 3 & 0.001 & 0.2 & 0.4 & 0.6 & 1.0 & 18.6 & 1.2 & 2.1 & 0.1 & 0.3 & 0.5 & 0.8 & 6.0 & 0.7 & 0.9 \\
\hline FL & 3 & 0.001 & 0.9 & 1.7 & 2.4 & 3.6 & 32.0 & 3.4 & 3.7 & 0.7 & 1.4 & 1.7 & 2.4 & 7.1 & 2.3 & 1.5 \\
\hline PHE & 3 & 0.001 & 5.4 & 14.1 & 20.3 & 35.1 & 297.2 & 32.3 & 39.4 & 6.4 & 9.9 & 14.8 & 19.4 & 84.6 & 19.5 & 15.8 \\
\hline ANT & 3 & 0.01 & 0.5 & 1.8 & 2.8 & 5.3 & 55.3 & 5.7 & 8.8 & 0.7 & 1.2 & 2.1 & 3.8 & 21.8 & 3.8 & 4.6 \\
\hline FLT & 4 & 0.001 & 2.1 & 11.1 & 19.2 & 37.4 & 404.1 & 36.8 & 56.7 & 2.7 & 7.8 & 11.9 & 17.3 & 103.3 & 18.6 & 20.4 \\
\hline PYR & 4 & 0.001 & 1.9 & 9.0 & 14.8 & 27.9 & 312.3 & 29.1 & 44.7 & 3.1 & 5.9 & 9.4 & 14.2 & 81.9 & 15.5 & 17.8 \\
\hline $\mathrm{BaA}$ & 4 & 0.1 & 0.8 & 4.9 & 8.5 & 17.4 & 210.7 & 19.1 & 32.3 & 1.0 & 3.1 & 5.6 & 8.3 & 89.1 & 11.2 & 16.8 \\
\hline CHR & 4 & 0.01 & 1.8 & 9.3 & 17.2 & 27.9 & 273.5 & 28.7 & 39.3 & 1.8 & 7.2 & 10.5 & 15.7 & 90.6 & 16.3 & 18.7 \\
\hline $\mathrm{BbF}$ & 5 & 0.1 & 2.5 & 17.3 & 26.6 & 49.8 & 365.8 & 42.6 & 50.7 & 2.1 & 14.4 & 21.1 & 34.0 & 200.2 & 33.2 & 37.1 \\
\hline $\mathrm{BkF}$ & 5 & 0.1 & 0.7 & 9.5 & 19.9 & 36.9 & 123.1 & 27.2 & 25.1 & 0.7 & 12.0 & 16.6 & 29.4 & 119.9 & 24.0 & 21.1 \\
\hline $\mathrm{BaP}$ & 5 & 1 & 0.8 & 5.3 & 9.3 & 19.4 & 201.9 & 21.1 & 34.1 & 0.8 & 3.7 & 6.0 & 12.5 & 135.1 & 14.1 & 23.1 \\
\hline IND & 6 & 0.1 & 1.2 & 7.7 & 12.2 & 23.5 & 236.6 & 24.6 & 36.2 & 1.2 & 6.2 & 8.8 & 19.3 & 191.1 & 19.3 & 30.0 \\
\hline DBA & 5 & 1 & DL & 1.4 & 2.3 & 4.8 & 56.4 & 5.0 & 8.0 & DL & 1.1 & 1.5 & 3.5 & 46.7 & 4.0 & 7.3 \\
\hline BghiP & 6 & 0.01 & 1.4 & 8.0 & 11.7 & 22.9 & 206.6 & 22.5 & 30.3 & 1.3 & 6.4 & 9.3 & 18.6 & 180.0 & 19.0 & 28.3 \\
\hline \multicolumn{3}{|c|}{ LMW PAHs } & 13.4 & 29.7 & 42.7 & 77.0 & 564.8 & 65.2 & 69.3 & 18.1 & 24.3 & 34.4 & 42.9 & 130.3 & 44.1 & 30.0 \\
\hline \multicolumn{3}{|c|}{ HMW PAHs } & 15.2 & 90.8 & 139.3 & 289.9 & 2085.7 & 256.6 & 344.0 & 17.2 & 68.2 & 105.3 & 158.2 & 1159.1 & 175.1 & 209.1 \\
\hline \multicolumn{3}{|c|}{$\sum$ PAHs } & 28.6 & 124.9 & 189.3 & 353.4 & 2571.9 & 321.8 & 408.2 & 37.5 & 94.2 & 145.2 & 215.9 & 1245.9 & 219.2 & 233.5 \\
\hline
\end{tabular}

$S D$ denotes standard deviation, $L M W P A H s$ denotes low molecular weight PAHs (two to three rings), $H M W P A H s$ denotes high molecular weight PAHs (four to six rings), $\sum P A H s$ denotes sum of the $16 \mathrm{PAH}$ concentrations, $D L$ denotes detection limit of the analysis method (Table S1), and TEF denotes toxic equivalency factor on the basis of BaP (Liao and Chiang 2006)

(Fig. 2). Soils originating from wood preservation plants were often found to be contaminated by PAHs because PAHs are the major active ingredient in wood preservative (Elgh-Dalgren et al. 2009). The second highest PAH concentration of $6981 \mathrm{ng} / \mathrm{g}$ was from a private backyard used as vegetable plot in a small village. Sludge application was speculated to be the reason of the high PAHs in the garden according to on-site inspection. The abnormal PAH concentrations in the two contaminated sites were most likely caused by direct pollution from point sources.

The five sampling sites with high PAH concentrations were ranked 1 to 5 in Table 2. It was noteworthy that the five sampling sites were all related to Shougang

Table 2 The sampling sites with high PAH concentrations and ILCRs in peri-urban Beijing (ng/g)

\begin{tabular}{llllllll}
\hline Rank & Land use & LMW PAHs & HMW PAHs & EPAHs & \multicolumn{2}{c}{$\begin{array}{c}\text { PPAHs } \\
\text { TEQ }\end{array}$} & ILCRs (adult) \\
& & & & ILCRs (child) \\
\hline Outlier A & Industrial area & 9907.8 & 68568.4 & $78476.1^{\mathrm{a}}$ & 10754 & $5.53 \times 10^{-5}$ & $2.77 \times 10^{-5}$ \\
Outlier B & Living area & 718.6 & 6262.9 & $6981.4^{\mathrm{a}}$ & 933 & $4.80 \times 10^{-6}$ & $2.41 \times 10^{-6}$ \\
1 & Industrial area & 564.8 & 2007.1 & 2571.9 & 286 & $1.47 \times 10^{-6}$ & $7.36 \times 10^{-7}$ \\
2 & Industrial area & 407.5 & 2085.7 & 2493.2 & 349 & $1.80 \times 10^{-6}$ & $9.01 \times 10^{-7}$ \\
3 & Industrial area & 227 & 1872.3 & 2099.3 & 342 & $1.76 \times 10^{-6}$ & $8.81 \times 10^{-7}$ \\
4 & Living area & 389.4 & 1656.7 & 2046 & 252 & $1.30 \times 10^{-6}$ & $6.50 \times 10^{-7}$ \\
5 & Industrial area & 252.3 & 1602.1 & 1854.4 & 266 & $1.37 \times 10^{-6}$ & $6.86 \times 10^{-7}$ \\
\hline
\end{tabular}

${ }^{\mathrm{a}}$ The two outliers were excluded from statistical analysis processes 


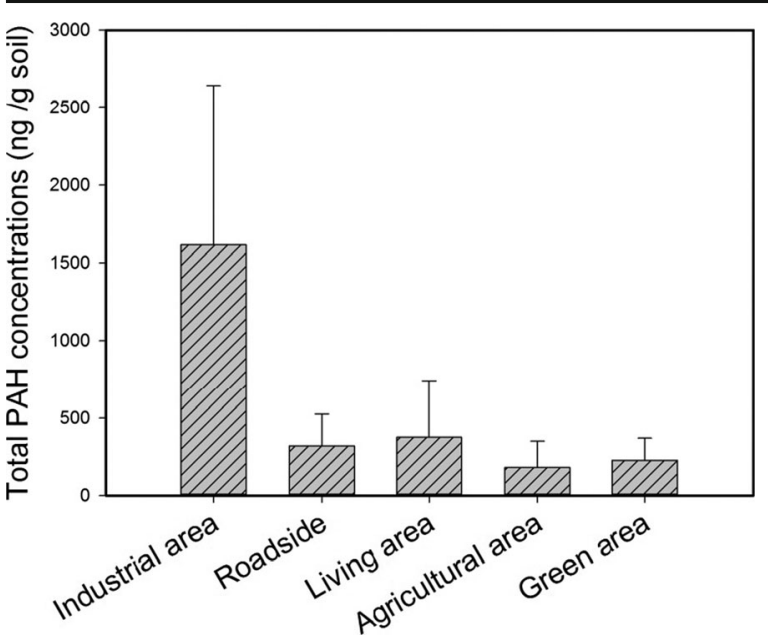

Fig. 3 The PAH concentrations in soils of peri-urban Beijing under various land uses (ng/g)

Corporation, which is one of China's largest steel companies, located in suburban Beijing. The no. 1 site measured was from northwest Beijing in the vicinity of the Shougang wire plant, and the nos. 2 to 5 sites were inside or close to the Shougang steel plant in the western area of Beijing (Fig. 2). The combustion processes in iron and steel making industries released plenty of PAHs into the environment and consequently elevated the PAH concentrations in the surrounding soils. Due to concerns over pollution, Beijing municipality moved out Shougang operations prior to the 2008 Olympics. Once deposited into soils, PAHs tend to be adsorbed to soil particles and are slow to undergo degradation, volatilization, or transfer. Therefore, soils contaminated by historical industrial activities can continue to threaten the health of residents even after the polluting factories have been shut down for years.

\section{PAH distribution in soils of various land use}

The soil PAH concentrations varied with land use categories in the suburban and rural areas of Beijing (Fig. 3). The industrial area had significantly higher soil PAH concentrations than the other land use categories $(p<0.01)$. The profiles of the 16 PAH congeners in different land uses were shown in Table 3. Industrial soils contained a slightly higher proportion of high molecular weight PAHs (HMW PAHs; four to six ring PAHs) compared with the soils of the other four land uses. The industrial areas were under the direct influence of the heavy industries in suburban Beijing. The coal combustion, incineration, and chemical processes in

Table 3 The profiles of PAH congeners in soils of peri-urban Beijing under various land uses

\begin{tabular}{|c|c|c|c|c|c|c|}
\hline & $\begin{array}{l}\text { Industrial area } \\
(\text { mean } \pm \mathrm{SD})\end{array}$ & $\begin{array}{l}\text { Roadside } \\
(\text { mean } \pm \mathrm{SD})\end{array}$ & $\begin{array}{l}\text { Living area } \\
(\text { mean } \pm \mathrm{SD})\end{array}$ & $\begin{array}{l}\text { Agricultural area } \\
(\text { mean } \pm \mathrm{SD})\end{array}$ & $\begin{array}{l}\text { Green area } \\
(\text { mean } \pm \mathrm{SD})\end{array}$ & $\begin{array}{l}\text { Total } \\
(\text { mean } \pm \mathrm{SD})\end{array}$ \\
\hline NAP (\%) & $3.4 \pm 2.6$ & $8.2 \pm 5.2$ & $9.3 \pm 7.4$ & $9.1 \pm 4.5$ & $8.9 \pm 7.0$ & $8.9 \pm 5.9$ \\
\hline ACPY (\%) & $1.9 \pm 1.5$ & $1.2 \pm 0.5$ & $1.2 \pm 0.7$ & $1.2 \pm 1.8$ & $1.3 \pm 1.2$ & $1.3 \pm 1.4$ \\
\hline $\mathrm{ACP}(\%)$ & $0.4 \pm 0.3$ & $0.4 \pm 0.2$ & $0.3 \pm 0.2$ & $0.4 \pm 0.2$ & $0.4 \pm 0.3$ & $0.4 \pm 0.2$ \\
\hline FL (\%) & $0.8 \pm 0.3$ & $1.3 \pm 0.7$ & $1.3 \pm 0.7$ & $1.4 \pm 0.7$ & $1.5 \pm 0.9$ & $1.4 \pm 0.7$ \\
\hline PHE (\%) & $8.3 \pm 3.3$ & $10.7 \pm 3.1$ & $10.9 \pm 3.3$ & $11.0 \pm 3.3$ & $11.6 \pm 3.4$ & $11.0 \pm 3.3$ \\
\hline ANT (\%) & $2.3 \pm 1.1$ & $1.7 \pm 0.4$ & $1.8 \pm 0.6$ & $1.5 \pm 0.4$ & $1.5 \pm 0.7$ & $1.6 \pm 0.6$ \\
\hline FLT (\%) & $12.1 \pm 2.8$ & $10.0 \pm 1.3$ & $9.7 \pm 2.9$ & $9.4 \pm 1.6$ & $10.5 \pm 2.0$ & $9.8 \pm 2.2$ \\
\hline PYR (\%) & $10.1 \pm 2.9$ & $8.0 \pm 1.3$ & $7.9 \pm 2.4$ & $7.3 \pm 1.3$ & $8.0 \pm 2.0$ & $7.7 \pm 1.9$ \\
\hline $\mathrm{BaA}(\%)$ & $6.9 \pm 1.5$ & $5.1 \pm 1.1$ & $5.0 \pm 1.5$ & $4.1 \pm 1.1$ & $4.6 \pm 1.4$ & $4.6 \pm 1.4$ \\
\hline CHR (\%) & $8.9 \pm 1.9$ & $8.1 \pm 1.4$ & $7.8 \pm 1.7$ & $8.2 \pm 2.0$ & $8.9 \pm 2.7$ & $8.2 \pm 2.0$ \\
\hline $\mathrm{BbF}(\%)$ & $13.0 \pm 2.9$ & $13.8 \pm 2.0$ & $13.3 \pm 2.7$ & $14.7 \pm 2.0$ & $13.5 \pm 2.5$ & $14.0 \pm 2.4$ \\
\hline $\mathrm{BkF}(\%)$ & $8.6 \pm 4.4$ & $10.7 \pm 4.6$ & $10.2 \pm 4.5$ & $11.2 \pm 4.7$ & $9.8 \pm 4.9$ & $10.6 \pm 4.7$ \\
\hline $\mathrm{BaP}(\%)$ & $7.2 \pm 1.7$ & $5.7 \pm 2.3$ & $5.5 \pm 1.8$ & $5.1 \pm 1.6$ & $5.1 \pm 1.5$ & $5.3 \pm 1.7$ \\
\hline IND (\%) & $7.7 \pm 1.7$ & $6.7 \pm 2.5$ & $7.3 \pm 2.2$ & $7.0 \pm 2.0$ & $6.6 \pm 1.7$ & $7.0 \pm 2.0$ \\
\hline DBA $(\%)$ & $1.9 \pm 0.7$ & $1.4 \pm 0.7$ & $1.4 \pm 0.5$ & $1.3 \pm 0.4$ & $1.2 \pm 0.4$ & $1.3 \pm 0.5$ \\
\hline BghiP (\%) & $6.5 \pm 2.8$ & $6.8 \pm 1.9$ & $7.1 \pm 2.1$ & $7.1 \pm 1.8$ & $6.5 \pm 1.3$ & $7.0 \pm 1.9$ \\
\hline LMW PAHs (\%) & $17.1 \pm 5.0$ & $23.6 \pm 8.4$ & $24.8 \pm 9.8$ & $24.6 \pm 7.0$ & $25.2 \pm 10.1$ & $24.5 \pm 8.5$ \\
\hline HMW PAHs (\%) & $82.9 \pm 5.0$ & $76.4 \pm 8.4$ & $75.2 \pm 9.8$ & $75.4 \pm 7.0$ & $74.8 \pm 10.1$ & $75.5 \pm 8.5$ \\
\hline
\end{tabular}


Fig. 4 Molecular composition ratio of PAHs in soils of periurban Beijing under various land uses

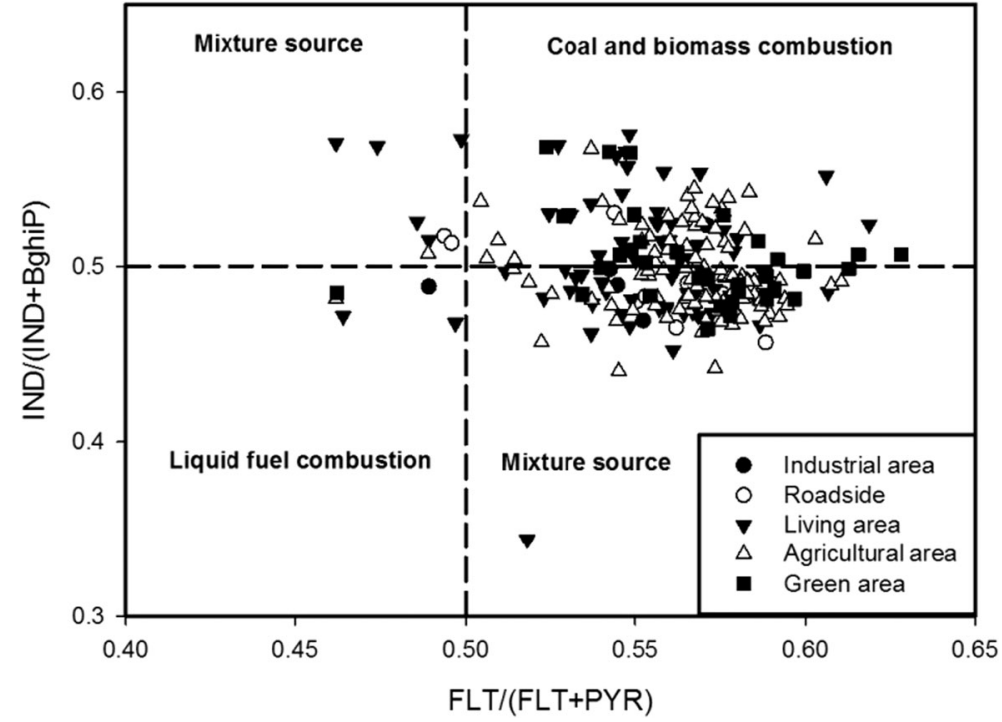

those areas emit abundant PAHs composed relatively higher proportion of HMW PAHs into the surrounding environment (Xu et al. 2005). Therefore, the soils around the industrial plants were heavily contaminated with anthropogenic PAHs, especially the HMW PAHs.

The average total PAH concentration in soils from the living areas was $375.3 \pm 366.8 \mathrm{ng} / \mathrm{g}$, which was significantly higher than that of the agricultural areas and the green areas $(p<0.01)$. Peng et al. (2012) reported that the average total PAH concentration in the residential soils of urban Beijing was $811 \pm 748 \mathrm{ng} / \mathrm{g}$. Cooking and winter heating in the living area would release extra PAHs to the local atmosphere. Therefore, it was predictable that the denser population would lead to higher PAH deposition in living areas. The average PAH concentrations of living areas were higher than that of all the sampling sites (Fig. S1), suggesting that human daily routines were one of major sources of PAHs in the suburban and rural areas.

The soil PAH concentrations in the agricultural areas and the green areas were $181.5 \pm 169.3$ and 228.3 $\pm 141.3 \mathrm{ng} / \mathrm{g}$, respectively. The results were comparable to the PAH concentrations of 311.3 and $310.7 \mathrm{ng} / \mathrm{g}$ measured, respectively, in the cultivated land and green areas surrounding Guanting Reservoir outside the northern sixth ring road of Beijing (Jiao et al. 2013). The low PAH concentrations in agricultural soils suggested that the farming activities were not the main cause of PAH accumulation in soils. The agricultural area and the green area could receive the deposition of airborne PAHs transported from the industrial areas or the downtown of Beijing. The green areas' vegetative cover had a relatively higher vertical structure than the agricultural area. The forests with their larger canopy were more efficient than agricultural crops in intercepting airborne PAHs, thus explaining the slightly higher $\mathrm{PAH}$ concentrations in the green areas.

The average total PAH concentrations were 320.3 $\pm 205.9 \mathrm{ng} / \mathrm{g}$ in the roadside soils of peri-urban Beijing (Fig. 3). In urban Beijing, the total PAH concentrations in soils of roadsides with heavy traffic and light traffic were $1026 \pm 726$ and $538 \pm 340 \mathrm{ng} / \mathrm{ng}$, respectively (Peng et al. 2012). The traffic emissions were identified as one of the major PAH sources in urban areas. In contrast, the traffic density in the peri-urban Beijing was much lower. No significant difference in PAH

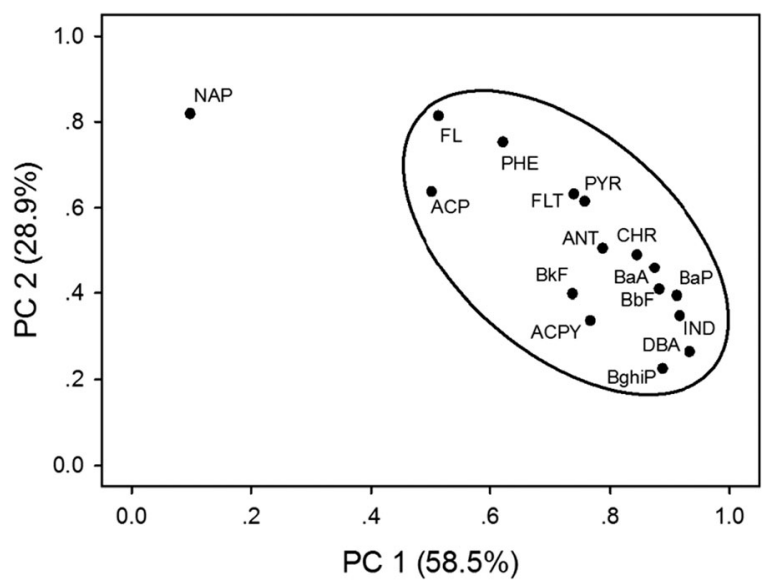

Fig. 5 Factor analysis of PAHs in soils of peri-urban Beijing 

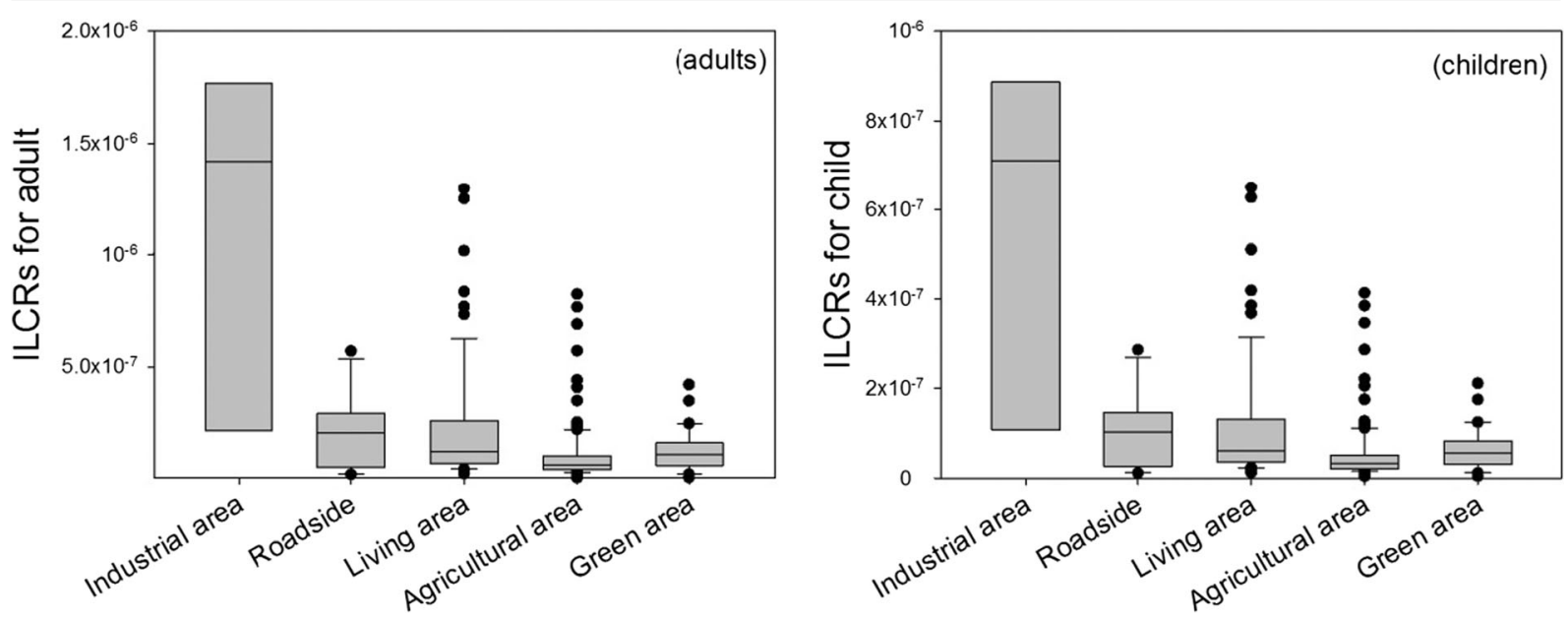

Fig. 6 The total ILCRs for adult and child exposed to PAHs in soils of peri-urban Beijing

concentrations was found between the roadside soils and the agricultural soils, indicating that transportation was not the major PAH source in the suburban and rural areas of Beijing.

\section{PAH source apportionment}

The compositions of PAH congeners in the soils can be used as fingerprints to identify the types of PAH sources. The HMW PAHs contributed 79.7 and $79.9 \%$ of the total PAH mass in suburban and rural soils of Beijing, respectively. The contributions of HMW PAHs in the current study were slightly lower than the ratio of $83 \%$ measured in urban Beijing (Peng et al. 2011). The HMW PAHs are the highly toxic group of PAHs related to combustion releases, while the low molecular weight PAHs (LMW PAHs, two to three ring PAHs) may derive from both incomplete combustion processes and volatilization of petroleum products (Chen et al. 2005). The high proportions of HMW PAHs suggested that the PAHs in suburban and rural areas of Beijing were mainly generated by combustion-related activities.

Analyzing the molecular composition ratio of PAHs was helpful in understanding the sources of PAHs in soils. For example, the ratio of IND vs. IND + BghiP and FLY vs. FLT + PYR could be used to distinguish the PAHs emitted from liquid fuel combustion or coal combustion based on empirical threshold values (Bucheli et al. 2004; Li et al. 2006). Figure 4 shows scattergrams of the two molecular ratios. Most of the sampling sites were clustered into two quadrants on the right. The PAHs in soils of the upper right quadrant indicated origins from coal and biomass combustion, such as coal usage in industrial activities and heating systems. The PAHs in soils of the lower right quadrant were derived from a mixture of coal combustion and liquid fuel combustion sources. This suggests that coal and biomass combustion were the dominant sources of PAHs in the suburban and rural areas of Beijing. Unlike the urban areas (Peng et al. 2011), traffic emissions were no longer the primary PAH sources in these areas. There was no significant difference in the sources of PAHs between the five land uses (Fig. 4). PAHs originating from urban areas, scattered coal stoves and other emission sources might be transported by airflow and diffused evenly across the boundaries of contiguous land uses.

Factor analysis was conducted to further explain the sources and pathways of PAH deposition in the soils. The 16 PAH congeners were classified into two principal components (PCs) accounting for $87.4 \%$ of the total data variances (Fig. 5). The first group, PC1, contained $15 \mathrm{PAH}$ congeners that originated mainly from combustion sources and prone to adsorb on soil particles, thus accumulating in soils for longer time. On the contrary, PC2 contained only NAP, the volatile PAH that has the highest mobility among the 16 PAH congeners. NAP could re-enter the atmosphere through soil-air exchange processes. Furthermore, NAP could be released from biologically sources and petroleum products such as deodorizer, mothball, and asphalt (Jia and Batterman 2010; Wilcke 2007; Zhu and Wang 2003). The major differences between PC1 and PC2 were the transportability and half-lives of the chemicals in soil media. Therefore, PC1 accounting for $58.5 \%$ of the $\mathrm{PAH}$ variance in the soils was indicative of the deposition of PAHs from combustion sources, meanwhile PC2 might 
indicate the re-distribution of PAH through soil-air exchange processes, which was responsible for $28.9 \%$ of the PAH variance in these soils.

\section{Potential risks}

The PAH congeners have different levels of toxicity toward human health. The concentrations of PAH congeners were highly correlated with the total PAH TEQ in the suburban and rural soils of Beijing $(p<0.01$; Table S3). Therefore, the concentration of each PAH congener such as PHE, ANT, and BaP could be used as the risk indicator for total PAHs.

Figure 6 shows the ILCR for adults and children according to the total PAH TEQ in the suburban and rural soils of Beijing. ILCRs lower than $10^{-6}$ are generally considered the virtually safe level, between $10^{-6}$ and $10^{-4}$ indicates a low risk level, and ILCRs exceeding $10^{-4}$ indicate marginal safety (USEPA 1996). The average ILCRs of adults and children in suburban and rural areas were lower than those in urban areas (Peng et al. 2011). For both adults and children, the 90th percentiles of ILCRs in the soils of the roadside, living areas, agricultural areas, and green areas were under the safety threshold of $10^{-6}$. In the industrial area, however, the soil PAHs would pose a low-level carcinogenic risk to the adults living in the surrounding areas. The $\mathrm{ILCR}_{\text {ingestion, }}$

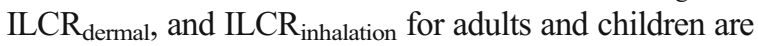
shown in Table S4. Generally, the ILCR dermal $_{\text {is }}$ the most important exposure pathway for adults while the $\mathrm{ILCR}_{\text {ingestion }}$ is more important for children. The $\mathrm{ILCR}_{\text {inhalation }}$ is negligible for both adults and children.

The ILCRs of the two outliers and five sampling sites with high PAH concentrations are shown in Table 2. The two outliers had considerably higher ILCRs than other sampling sites and posed low-level risks to the health of adults and children. Low health risks were also found in the other five locations. Therefore, although most of the area of suburban Beijing could be considered as virtually safe for inhabitation in terms of the soil PAH concentrations, a few areas affected by point sources or previously industrial activities should be of concern.

\section{Conclusions}

We investigated the sources and distributions of PAHs in suburban and rural soils of Beijing. The impacts of land use categories and industrial plants on $\mathrm{PAH}$ accumulation were discussed in detail. Clear decreases of soil PAH concentrations were found along the urbansuburban-rural gradient. Several sampling sites with high PAH concentrations were attributed to industrial activities such as iron and steel making as well as wood preservative production. The industrial areas and the living areas had higher soil PAH concentrations than the agricultural areas and the green areas in peri-urban Beijing. The PAHs in suburban and rural soils were mainly released from coal and biomass combustion. Health risk assessment showed that the soil PAH concentrations were at a safe level in most of the sampling areas, but a few sites affected by previously industrial activities showed low-level health risks. Cautions should be paid to those abandoned industrial sites, which are being converted to urban residential areas during the urbanization process.

Acknowledgments We gratefully acknowledge financial support provided by the National Natural Science Foundation of China (Grant No. 41401588).

\section{References}

Aichner, B., Glaser, B., \& Zech, W. (2007). Polycyclic aromatic hydrocarbons and polychlorinated biphenyls in urban soils from Kathmandu, Nepal. Organic Geochemistry, 38, 700715.

Augusto, S., Máguas, C., Matos, J., Pereira, M. J., Soares, A., \& Branquinho, C. (2009). Spatial modeling of PAHs in lichens for fingerprinting of multisource atmospheric pollution. Environmental Science \& Technology, 43, 7762-7769.

Bu, Q., Zhang, Z., Lu, S., \& He, F. (2009). Vertical distribution and environmental significance of PAHs in soil profiles in Beijing, China. Environmental Geochemistry and Health, 31, 119-131.

Bucheli, T. D., Blum, F., Desaules, A., \& Gustafsson, O. (2004). Polycyclic aromatic hydrocarbons, black carbon, and molecular markers in soils of Switzerland. Chemosphere, 56, 1061-1076.

Chen, S.-C., \& Liao, C.-M. (2006). Health risk assessment on human exposed to environmental polycyclic aromatic hydrocarbons pollution sources. Science of the Total Environment, 366, 112-123.

Chen, L., Ran, Y., Xing, B., Mai, B., He, J., Wei, X., Fu, J., \& Sheng, G. (2005). Contents and sources of polycyclic aromatic hydrocarbons and organochlorine pesticides in vegetable soils of Guangzhou, China. Chemosphere, 60, 879-890.

Elgh-Dalgren, K., Arwidsson, Z., Camdzija, A., Sjoberg, R., Ribe, V., Waara, S., Allard, B., von Kronhelm, T., \& van Hees, P. A. W. (2009). Laboratory and pilot scale soil washing of PAH and arsenic from a wood preservation site: changes in concentration and toxicity. Journal of Hazardous Materials, 172, 1033-1040. 
Feng, S., Cao, Z., Yang, Y., Wei, G., \& Wang, X. M. (2013). Polycyclic aromatic hydrocarbons, heavy metals, and genotoxicity of the suburban soils from Guangzhou, China. Polycyclic Aromatic Compounds, 33, 501-518.

He, F., Zhang, Z., Wan, Y., Lu, S., Wang, L., \& Bu, Q. (2009). Polycyclic aromatic hydrocarbons in soils of Beijing and Tianjin region: vertical distribution, correlation with TOC and transport mechanism. Journal of Environmental Sciences, 21, 675-685.

Heywood, E., Wright, J., Wienburg, C. L., Black, H. I. J., Long, S. M., Osborn, D., \& Spurgeon, D. J. (2006). Factors influencing the national distribution of polycyclic aromatic hydrocarbons and polychlorinated biphenyls in British soils. Environmental Science \& Technology, 40, 7629-7635.

Jia, C., \& Batterman, S. (2010). A critical review of naphthalene sources and exposures relevant to indoor and outdoor air. International Journal of Environmental Research and Public Health, 7, 2903-2939.

Jiao, W., Wang, T., Lu, Y., Chang, A., \& Chen, W. (2013). Multifactors influencing the spatial distribution of polycyclic aromatic hydrocarbons in soils surrounding drinking water protection zone. Journal of Environmental Sciences (China), 25, 1643-1648.

Li, X.-h., Ma, L.-1., Liu, X.-f., Fu, S., Cheng, H.-x., \& Xu, X.-b. (2006). Polycyclic aromatic hydrocarbon in urban soil from Beijing, China. Journal of Environmental Sciences, 18, 944 950.

Liao, C.-M., \& Chiang, K.-C. (2006). Probabilistic risk assessment for personal exposure to carcinogenic polycyclic aromatic hydrocarbons in Taiwanese temples. Chemosphere, 63, 1610-1619.

Liu, Y., Liu, L., Lin, J.-M., Tang, N., \& Hayakawa, K. (2006). Distribution and characterization of polycyclic aromatic hydrocarbon compounds in airborne particulates of East Asia. China Particuology, 4, 283-292.

Liu, S. J., Lu, Y. L., Wang, T. Y., Xie, S. W., Jones, K. C., \& Sweetman, A. J. (2014). Using gridded multimedia model to simulate spatial fate of Benzo alpha pyrene on regional scale. Environment International, 63, 53-63.

Ma, L. L., Chu, S. G., Wang, X. T., Cheng, H. X., Liu, X. F., \& Xu, X. B. (2005). Polycyclic aromatic hydrocarbons in the surface soils from outskirts of Beijing, China. Chemosphere, 58, $1355-1363$.

Ma, W.-L., Liu, L.-Y., Tian, C.-G., Qi, H., Jia, H.-L., Song, W.-W., \& Li, Y.-F. (2015). Polycyclic aromatic hydrocarbons in Chinese surface soil: occurrence and distribution. Environmental Science and Pollution Research, 22, 41904200 .

Nam, J. J., Thomas, G. O., Jaward, F. M., Steinnes, E., Gustafsson, O., \& Jones, K. C. (2008). PAHs in background soils from Western Europe: influence of atmospheric deposition and soil organic matter. Chemosphere, 70, 1596-1602.

Peng, C., Chen, W., Liao, X., Wang, M., Ouyang, Z., Jiao, W., \& Bai, Y. (2011). Polycyclic aromatic hydrocarbons in urban soils of Beijing: status, sources, distribution and potential risk. Environmental Pollution, 159, 802-808.

Peng, C., Ouyang, Z., Wang, M., Chen, W., \& Jiao, W. (2012). Vegetative cover and PAHs accumulation in soils of urban green space. Environmental Pollution, 161, 36-42.

Peng, C., Ouyang, Z., Wang, M., Chen, W., Li, X., \& Crittenden, J. C. (2013). Assessing the combined risks of PAHs and metals in urban soils by urbanization indicators. Environmental Pollution, 178, 426-432.

Peng, C., Wang, M., Chen, W., \& Chang, A. C. (2015). Mass balance-based regression modeling of PAHs accumulation in urban soils, role of urban development. Environmental Pollution, 197, 21-27.

Ravindra, K., Sokhi, R., \& Van Grieken, R. (2008). Atmospheric polycyclic aromatic hydrocarbons: source attribution, emission factors and regulation. Atmospheric Environment, 42, 2895-2921.

Reimann, C., \& Filzmoser, P. (2000). Normal and lognormal data distribution in geochemistry: death of a myth. Consequences for the statistical treatment of geochemical and environmental data. Environmental Geology, 39, 1001-1014.

Sun, J.-H., Wang, G.-L., Chai, Y., Zhang, G., Li, J., \& Feng, J. (2009). Distribution of polycyclic aromatic hydrocarbons (PAHs) in Henan Reach of the Yellow River, Middle China. Ecotoxicology and Environmental Safety, 72, 1614-1624.

Tao, S., Cui, Y. H., Xu, F., Li, B. G., Cao, J., Liu, W., Schmitt, G., Wang, X. J., Shen, W., Qing, B. P., \& Sun, R. (2004). Polycyclic aromatic hydrocarbons (PAHs) in agricultural soil and vegetables from Tianjin. Science of the Total Environment, 320, 11-24.

USEPA. (1991). Risk assessment guidance for superfund, volume 1, human health evaluation manual (Part B, development of risk-based preliminary remediation goals). EPA/540/R-92/ 003 Publication 9285.7-01B.

USEPA. (1996). Soil screening guidance: user's guide (second edition). In Agency, U.S.E.P (Ed.), Office of emergency and remedial response (2nd ed., p. 20460). Washington, DC: United States Environmental Protection Agency.

Vane, C. H., Kim, A. W., Beriro, D. J., Cave, M. R., Knights, K., Moss-Hayes, V., \& Nathanail, P. C. (2014). Polycyclic aromatic hydrocarbons (PAH) and polychlorinated biphenyls (PCB) in urban soils of Greater London, UK. Applied Geochemistry, 51, 303-314.

Wang, Z. (2007). Regional study on soil polycyclic aromatic hydrocarbons in Liaoning: patterns, sources and cancer risks, Dalian University of Technology. Dalian: Dalian University of Technology.

Wang, Z., Chen, J., Qiao, X., Yang, P., Tian, F., \& Huang, L. (2007). Distribution and sources of polycyclic aromatic hydrocarbons from urban to rural soils: a case study in Dalian, China. Chemosphere, 68, 965-971.

Wang, W., Massey Simonich, S. L., Xue, M., Zhao, J., Zhang, N., Wang, R., Cao, J., \& Tao, S. (2010). Concentrations, sources and spatial distribution of polycyclic aromatic hydrocarbons in soils from Beijing, Tianjin and surrounding areas, North China. Environmental Pollution, 158, 1245-1251.

Wang, W., Huang, M.-j., Kang, Y., Wang, H.-s., Leung, A. O. W., Cheung, K. C., \& Wong, M. H. (2011). Polycyclic aromatic hydrocarbons (PAHs) in urban surface dust of Guangzhou, China: status, sources and human health risk assessment. Science of the Total Environment, 409, 4519-4527.

Wang, X. T., Miao, Y., Zhang, Y., Li, Y. C., Wu, M. H., \& Yu, G. (2013). Polycyclic aromatic hydrocarbons (PAHs) in urban soils of the megacity Shanghai: occurrence, source apportionment and potential human health risk. Science of the Total Environment, 447, 80-89.

Wang, X.-T., Chen, L., Wang, X.-K., Lei, B.-L., Sun, Y.-F., Zhou, J., \& Wu, M.-H. (2015). Occurrence, sources and health risk 
assessment of polycyclic aromatic hydrocarbons in urban (Pudong) and suburban soils from Shanghai in China. Chemosphere, 119, 1224-1232.

Wilcke, W. (2007). Global patterns of polycyclic aromatic hydrocarbons (PAHs) in soil. Geoderma, 141, 157-166.

Wong, F., Harner, T., Liu, Q.-T., \& Diamond, M. L. (2004). Using experimental and forest soils to investigate the uptake of polycyclic aromatic hydrocarbons (PAHs) along an urban-rural gradient. Environmental Pollution, 129, 387-398.

Wu, S., Xia, X., Lin, C., Chen, X., \& Zhou, C. (2010). Levels of arsenic and heavy metals in the rural soils of Beijing and their changes over the last two decades (1985-2008). Journal of Hazardous Materials, 179, 860-868.
Xiao, Y., Tong, F., Kuang, Y., \& Chen, B. (2014). Distribution and source apportionment of polycyclic aromatic hydrocarbons (PAHs) in forest soils from urban to rural areas in the Pearl River Delta of southern China. International Journal of Environmental Research and Public Health, 11, 2642-2656.

Xu, S., Liu, W., \& Tao, S. (2005). Emission of polycyclic aromatic hydrocarbons in China. Environmental Science \& Technology, 40, 702-708.

Zheng, W., Lichwa, J., \& Yan, T. (2011). Impact of different land uses on polycyclic aromatic hydrocarbon contamination in coastal stream sediments. Chemosphere, 84, 376-382.

Zhu, L., \& Wang, J. (2003). Sources and patterns of polycyclic aromatic hydrocarbons pollution in kitchen air, China. Chemosphere, 50, 611-618. 